\title{
Editorial
}

\section{ESTUDOS DO ESTADO DA ARTE DA PESQUISA SOBRE O PROFESSOR QUE ENSINA MATEMÁTICA}

\author{
Vanessa Moreira Crecci ${ }^{1}$ \\ Adair Mendes Nacarato ${ }^{2}$ \\ Dario Fiorentini ${ }^{3}$
}

Nos últimos anos, observou-se um crescimento significativo dos estudos sobre o professor que ensina matemática (PEM). Isto significa dizer que tem aumentado o número de pesquisas que têm como foco de estudo: a aprendizagem docente e o desenvolvimento profissional do PEM; as concepções, crenças, atitudes e representações do PEM; os saberes, competências e conhecimentos profissionais do PEM; a identidade e profissionalidade docente; as condições, características, performance e desempenho docentes; as práticas letivas ou profissionais do PEM; as disciplinas, cursos, instituições, programas e processo de formação inicial e continuada; história da formação e história de professores que ensinam matemática; o formador de professores que ensinam matemática etc.

Para mapear, descrever, sistematizar e discutir essa crescente produção científica sobre o PEM, tornam-se necessários estudos de revisão sistemática, tais como: mapeamento; estado da arte da pesquisa ou estado do conhecimento; metanálise; e metassíntese. Há mais de duas décadas, o Grupo de Estudo e Pesquisa sobre a formação do Professor de Matemática (GEPFPM) vêm desenvolvendo e orientando pesquisas nessas modalidades de revisão sistemática, dentre as quais se destacam os estudos de Fiorentini (1994), Ferreira et al. (2000), Fiorentini et al. (2002) e Passos et al. (2006).

Motivado por essa experiência e pelo desafio de compreender epistemologicamente o campo de estudo relativo ao professor que ensina matemática, o GEPFPM tem participado ativamente da organização dos fóruns de discussão da pesquisa em Educação Matemática, intitulado: "Parâmetros Balizadores das Pesquisas em Educação Matemática no Brasil". Estes

\footnotetext{
1 Doutora em Educação pela Universidade Estadual de Campinas. Professora da Faculdade SESI-SP de Educação, Brasil. E-mail: vanessa.crecci@faculdadesesi.edu.br.

2 Doutora em Educação pela Universidade Estadual de Campinas. Professora da Universidade São Francisco, Brasil.Email: adamn@terra.com.br.

3 Doutor em Educação pela Universidade Estadual de Campinas. Professor da Universidade Estadual de Campinas, Brasil. E-mail: dariofiore@terra.com.br.
} 
fóruns congregam diferentes pesquisadores da área de Educação Matemática. O primeiro foi realizado em 2011 na Unesp/Rio Claro e o segundo na FE/Unicamp em 2013, envolvendo grupos de discussão de acordo com as temáticas presentes nas pesquisas em Educação Matemática. Observou-se que, em ambos os eventos, o maior número de participantes foi relativo à pesquisa sobre formação de professores, destacando-se nas discussões desse grupo a falta de clareza sobre o que caracteriza o campo ou objeto de estudo do professor e sua formação. Isso mobilizou o grupo a propor um projeto de pesquisa de âmbito nacional, visando mapear, descrever, analisar e compreender esse campo de estudo. O GEPFPM assumiu a responsabilidade de coordenar esse projeto nacional, envolvendo a participação de equipes de pesquisa de todas as regiões do Brasil. Esse Fórum teve continuidade e sua terceira edição ocorreu, em 2015, na PUC-São Paulo e, a quarta, em 2017, na UFSCar, campus São Carlos.

Decorrente das discussões do segundo Fórum, em 2013, o GEPFPM elaborou e submeteu um Projeto Universal ao CNPq (486505/2013-8), intitulado "Mapeamento e Estado da Arte da Pesquisa Brasileira sobre o Professor que Ensina Matemática", tendo como objetivo principal: mapear, descrever, sistematizar as pesquisas brasileiras produzidas no âmbito dos programas de Pós-Graduação stricto sensu das áreas de Educação e Ensino da CAPES, no período de 2001 a 2012.

O projeto teve início em outubro do mesmo ano e contou com a participação direta de 36 pesquisadores vinculados a sete equipes regionais/estaduais: Centro-Oeste; Nordeste; Norte; Sul; Minas Gerais; Rio de Janeiro/Espírito Santo; e São Paulo. Essas equipes foram organizadas de acordo com a quantidade de programas de pós-graduação das áreas de Educação e Ensino. Além disso, o projeto contou com a colaboração de especialistas externos que participaram, na Unicamp, de três seminários nacionais de estudo e discussão de trabalhos de pesquisa do projeto.

O desenvolvimento e os resultados da primeira fase desse estudo podem ser conferidos no e-book intitulado "Mapeamento da pesquisa acadêmica brasileira sobre o professor que ensina Matemática: período 2001 - 2012”, organizado por Fiorentini, Passos e Lima (2016).

Os pesquisadores envolvidos no projeto desenvolveram os capítulos que compõem a obra e apresentam, com detalhes, o desenvolvimento do Projeto Universal em cada uma das regionais, bem como, discussões sobre a configuração do campo de estudo do PEM, com destaque para seus principais contextos e focos de pesquisa, além de realizar um balanço das tendências metodológicas e temáticas das pesquisas mapeadas.

$\mathrm{Na}$ segunda fase do projeto, foram realizados estudos de revisão sistemática de pesquisas sobre temas ou problemas específicos e de interesse dos pesquisadores envolvidos. Parte significativa dos trabalhos que compõem este dossiê temático da revista Zetetiké é produto deste projeto. Embora a organização deste número especial tenha relação com o projeto citado, os editores consideraram pertinente abrir oportunidade, mediante edital, para 
que outros pesquisadores que realizam estudos de revisão sistemática de pesquisas sobre o professor que ensina matemática pudessem também submeter trabalhos. Assim, pudemos reunir, neste número especial, 10 artigos que passaram pela avaliação e aprovação de dois pareceristas da revista, sendo que oito desses foram desenvolvidos no contexto do projeto liderado pelo GEPFPM. Cabe, entretanto, esclarecer que a comissão editorial da revista Zetetiké, ao considerar o alto número de artigos submetidos a esse dossiê, optou por publicálos em dois volumes: este que concentra um maior número de artigos e, no próximo, com os artigos restantes que se encontram em processo final de avaliação e revisão.

Os 10 artigos deste dossiê temático contemplam quatro diferentes perspectivas de estudo do PEM. A primeira perspectiva reúne investigações que analisam as pesquisas que têm como foco de estudo o professor que ensina matemática (sua história ou identidade) ou o formador desse professor. Ou seja, trata-se de um foco de estudo ainda emergente ou pouco investigado, se comparado com outros focos relacionados à formação docente.

O artigo que abre esta perspectiva é o de Flávia Cristina Figueiredo Coura (UFSJ) e Cármen Lúcia Brancaglion Passos (UFSCar) e que tem por título "Estado do Conhecimento sobre o Formador de Professores de Matemática no Brasil". O objetivo deste estudo é descrever e sistematizar o conhecimento produzido pelas dissertações e teses concluídas no período de 2001 a 2012 e que produziram análises e conhecimentos sobre o formador de professores de Matemática. O corpus de análise deste estudo é composto por 30 pesquisas agrupadas em duas temáticas: 1) Atuação ou pensamento do formador de professores de matemática; e 2) Formação, aprendizagem, desenvolvimento ou constituição profissional do formador de professores de matemática.

O trabalho de Ênio Freire de Paula (IFSP) e Márcia Cristina de Costa Trindade Cyrino (UEL) tem por título: "Identidade Profissional de Professores que Ensinam Matemática: Panorama de Pesquisas Brasileiras entre 2001-2012”. Os pesquisadores descrevem e analisam as perspectivas teórico-metodológicas utilizadas por 15 dissertações e teses brasileiras que têm como foco de estudo a identidade profissional de professores que ensinam matemática, bem como, destacam os principais resultados obtidos por essas pesquisas.

No artigo intitulado: "Histórias da Formação e de Professores que Ensinam Matemática: possíveis aproximações teórico-metodológicas", as autoras Adair Mendes Nacarato (USF), Andréia Maria Pereira de Oliveira (UFBA) e Déa Nunes Fernandes (IFMA) analisaram 45 pesquisas, buscando identificar as perspectivas metodológicas e os referenciais teóricos utilizados a fim de verificar se as pesquisas que focam nas histórias de professores que ensinam Matemática se aproximam dos estudos biográficos. Para isso, organizaram as pesquisas em dois focos: "História da formação do professor que ensina Matemática" e "História do professor que ensina Matemática", com o intuito de analisar o que os aproxima ou os afasta. 
A segunda e a terceira perspectiva de estudos do PEM focam mais especificamente a formação de professores, sendo três relativas à formação inicial (segunda perspectiva) e três relativas à formação continuada (terceira perspectiva).

O primeiro artigo relativo à formação inicial tem por título "Estágio Curricular Supervisionado nas Licenciaturas em Matemática: Reflexões sobre as Pesquisas Brasileiras" e tem como autores: Anemari Roesler Luersen Vieira Lopes (UFSM); Maria Auxiliadora Vilela Paiva (IFES); Patrícia Sândalo Pereira (UFMS); Simone Pozebon (UFSM); e Wellington Lima Cedro (UFG). O objetivo principal deste estudo é mapear, descrever e analisar os objetivos e principais resultados e conclusões das pesquisas voltadas ao Estágio Curricular Supervisionado. No total, foram analisadas 20 pesquisas, agrupadas em cinco categorias: 1) estágio curricular supervisionado: metodologias de ensino em foco; 2) organização e desenvolvimento do estágio curricular supervisionado; 3) o estágio curricular supervisionado como espaço de aprendizagem da docência; 4) o estágio curricular supervisionado como espaço de reflexão e construção de saberes docentes; e 5) o papel do estágio curricular supervisionado na identidade profissional. Um aspecto destacado pelos autores nas discussões finais e conclusões é o papel ou a função do estágio supervisionado na relação entre a escola da Educação Básica e a Universidade.

O segundo artigo que analisa pesquisas com foco na formação inicial é o de Ana Maria Carneiro Abrahão (UERJ) e Sandra Aparecida Fraga da Silva (UFES) e tem por título "Pesquisas sobre a Formação Inicial do Professor que Ensina Matemática no Princípio da Escolarização". Trata-se de um trabalho que tem como corpus de análise 59 dissertações e teses que investigam a formação do professor que ensina matemática nos anos iniciais e na educação infantil. $\mathrm{Na}$ análise, as pesquisadoras tentam apresentar uma visão panorâmica sobre a concentração e a distribuição desses trabalhos pelas diversas regiões do Brasil e identificar quais tendências temáticas são privilegiadas nesses estudos, bem como seus principais resultados. Apontam, como resultados, problemas em relação aos programas curriculares, às práticas tradicionais, ao distanciamento entre universidade e escola básica, bem como, algumas possibilidades para aprimorar a formação para a docência matemática no princípio da escolarização.

A pesquisadora Rute Elizabete de Souza Rosa Borba (UFPE), no artigo intitulado "Formação Inicial e Continuada de Professores que Ensinam Matemática na Escolarização Inicial", tem por objetivo discutir cinco dissertações de mestrado identificadas das áreas de Ensino e de Educação, concluídas no período de 2008 a 2012, que tratam tanto da formação inicial quanto da formação continuada de professores que ensinam Matemática nos anos iniciais de escolarização. Na produção dos resultados de sua pesquisa, Rute discute a articulação entre a formação inicial e a formação continuada e o estabelecimento de parcerias cooperativas entre profissionais de fora e de dentro da escola, incluindo-se aí pesquisadores de IES e os professores dos distintos níveis de ensino da escola.

A terceira perspectiva - relativa à formação continuada do PEM - reúne também três pesquisas, sendo a primeira produzida pelas pesquisadoras Ana Cristina Ferreira (UFOP), 
DOI: http://dx.doi.org/10.20396/zet.v25i1.8649175

Ana Teresa de Carvalho Correa de Oliveira (UFRJ) e Cirléia Pereira Barbosa (IFMG) e que tem por título: "O professor que ensina matemática como foco de estudo em mestrados profissionais brasileiros". Para analisar as 96 dissertações de programas de mestrado profissional produzidas no período de 2002 a 2012, a pesquisa busca compreender como o pesquisador, que é um professor, percebe os participantes de seu estudo e se relaciona com eles.

O segundo estudo da terceira perspectiva é de autoria de Dario Fiorentini (Unicamp) e Vanessa Moreira Crecci (Faculdade SESI-SP de Educação), e tem por título "Metassíntese de pesquisas sobre conhecimentos/saberes na formação continuada de professores que ensinam matemática". Tendo por objetivo compreender o modo como as pesquisas brasileiras sobre formação continuada concebem e investigam os saberes e conhecimentos profissionais de professores que ensinam matemática e sua relação com as práticas profissionais, os pesquisadores, primeiramente, mapearam somente teses de doutorado sobre formação continuada relativas ao Projeto de "Mapeamento e Estado da Arte da Pesquisa Brasileira sobre o Professor que Ensina Matemática", no período 2001-2012. Em seguida, selecionaram 13 pesquisas que abordam os conhecimentos e saberes profissionais do professor que ensina matemática e que constituem o corpus da revisão sistemática deste estudo do tipo metassíntese. Para a produção dos resultados desse estudo, os autores sintetizam e discutem diferentes tendências e compreensões acerca do uso e da especificidade e natureza dos saberes e conhecimentos profissionais do PEM e de sua relação com as práticas profissionais docentes.

O último artigo relativo à formação continuada intitula-se: "Mapeamento de Pesquisas sobre Aprendizagem Docente em Comunidades de Prática Constituídas no Obeduc" e tem como autores Douglas da Silva Tinti (UNICID) e Ana Lúcia Manrique (PUC$\mathrm{SP})$. Neste estudo, com o intuito de compreender as aprendizagens docentes dos professores que ensinam Matemática, participantes do OBEDUC, e o modo como cada comunidade se constituiu, os autores analisaram 06 pesquisas desenvolvidas no contexto do Programa Observatório da Educação (OBEDUC) e que adotaram como referencial teórico a Teoria Social da Aprendizagem.

A quarta perspectiva de pesquisa do PEM possui apenas um artigo e diferencia-se dos anteriores por fazer um recorte temático relativo ao professor que ensina Estatística, Probabilidade e Combinatória, envolvendo, porém, todas as perspectivas anteriores. E esta é também a razão pela qual escolhemos este artigo para fechar o número temático. Trata-se do estudo de Rodrigo Medeiros dos Santos (UFOPA), intitulado "Balanço das Pesquisas sobre Formação/Prática de Professores que Ensinam Estatística, Probabilidade e Combinatória", e que tem por objetivo desenvolver um balanço das teses e dissertações produzidas em programas brasileiros de pós-graduação até o ano de 2015, e que investigam a temática da formação/prática de professores que ensinam os conteúdos de Estatística, Probabilidade e Combinatória. Tendo como corpus de análise 29 pesquisas, estas foram analisadas, a partir de quatro categorias temáticas: desenvolvimento profissional e formação inicial/continuada; 
prática docente; conhecimento profissional e saberes práticos; e Formação/Prática mediada por grupos colaborativos. Em cada uma dessas categorias, o autor apresenta e analisa os aspectos metodológicos e os resultados dos estudos de cada categoria.

Esperamos que os artigos aqui publicados possam contribuir para a compreensão e o debate sobre a formação do professor que ensina matemática, em seus diferentes níveis de ensino, bem como subsidiar outras pesquisas e motivar outros pesquisadores a desenvolverem estudos de revisão sistemática de pesquisas sobre o professor que ensina matemática.

\section{Referências}

Fiorentini, D. (1994). Rumos da pesquisa brasileira em educação matemática: o caso da produção científica em cursos de Pós-graduação. Tese de Doutorado em Educação. Campinas: Universidade Estadual de Campinas (Unicamp).

Ferreira, A. C., Lopes, C. A. E., Fiorentini, D., Jaramillo, D., Melo, G. F. A., Carvalho, V. E \& Santos-Wagner, V. M. (2000). Estado da arte e da pesquisa brasileira sobre formação de professores que ensinam matemática: uma primeira aproximação. In: Livro de Resumos do I SIPEM. Serra Negra, SBEM, pp. 264-271.

Fiorentini, D., Nacarato, A. M., Ferreira, A. C., Lopes, C. S., Freitas, M. T. M., \& Miskulin, R. G. S. (2002). Formação de professores que ensinam matemática: um balanço de 25 anos da pesquisa brasileira. Educação em Revista, 36, 137-160.

Fiorentini, D., Passos, C. L. B \& Lima, R. C. R. (Org.). (2016) Mapeamento da pesquisa acadêmica brasileira sobre o professor que ensina Matemática: Período 2001 a 2012. Campinas: FE-Unicamp. https://www.fe.unicamp.br/pf-fe/pf/subportais/biblioteca/fev2017/e-book-mapeamento-pesquisa-pem.pdf.

Passos, C.L.B., Nacarato, A. M., Fiorentini, D., Miskulin, R.G.S., Grando, R. C., Megid, M. A. B., Freitas, M.T.M. \& Melo, M. V. (2006). Desenvolvimento profissional do professor que ensina matemática: uma metanálise de estudos brasileiros. Quadrante (Lisboa), 15, 193-219. 